\title{
Theorising Strategic Investment Decision-Making using Strong
}

\section{Structuration Theory}

\begin{abstract}
Purpose - In the field of strategic investment decision-making (SIDM) a body of research has grown up via international case studies and organisation-based fieldwork. However, there has been little systematic theorisation around SIDM processes and practices. This paper aims to show how strong structuration theory (SST) can be employed to guide how future SIDM studies are conducted and theorised.
\end{abstract}

Design/methodology/approach - We draw upon the concepts from SST to reanalyse prior empirically based work. We apply SST-informed analysis to four SIDM case studies selected from the total of 18 published over the period 1970-2016 to explore the utility of SST compared with other approaches.

Findings - Our analysis highlights the role of agents' knowledgeability and position-practice relations in strategic investment decision-making, which has largely been neglected by prior studies. We demonstrate the potential of SST to inform meso-level SIDM theorising by applying it to four published case studies. Whilst we argue for the adoption of SST, we also identify key methodological and conceptual issues in using SST in SIDM research.

Research limitations/implications - Our examples and recommendations could assist management accounting researchers, particularly those engaged in case studies and organisational fieldwork, to build knowledge via the improved comparison, integration and theorisation of cases undertaken by different researchers in different contexts.

Originality/value -We offer a bridge between SST concepts and case study evidence for theorising, carrying out and analysing case study and field research on SIDM. 


\section{Introduction}

An organisation's strategy both shapes and is shaped by its investments in capital assets. Hence, strategic investment decision-making (SIDM) - defined as decision-making about "substantial investments that involve high levels of risk, produce hard-to-quantify (or intangible) outcomes, and have a significant long-term impact on corporate performance" (Alkaraan and Northcott, 2006, p. $150)$ - is an important part of management accounting research.

Over recent decades, a body of SIDM case studies and organisation-based fieldwork has emerged from around the world (e.g. King, 1975; Mintzberg et al., 1976; Harris, 1999; Maritan, 2001; Harris et al., 2009). However, there has been little systematic comparison of these studies to support theory building around SIDM processes and practices. Berry and Otley (2004, p. 244) have noted that this is a problem shared by many areas of accounting research that employ qualitative methods:

"theory building from a number of qualitative case research studies is potentially difficult because the researchers have worked from different methodological stances and hence their research findings may complement rather than build on each other."

This concern is raised again in Otley's (2016, p. 5) observation that qualitative (often interviewbased) studies are difficult to compare and aggregate, and is echoed by Hopwood (2009, p. 890), who expressed a desire to see "more cumulative patterns of research" in the accounting literature. While not wishing to duplicate recent literature reviews, it is relevant to highlight some key issues from prior SIDM research. For example, Haka (2007) has pointed out the need for a more holistic approach to examining the factors that shape SIDM, in particular paying more attention to external influences. Her literature review of over 150 studies, which traced the evolution of research on capital budgeting and investment appraisal from the 1950s to 2004, identified very few practicebased studies that examined the lived experiences of decision-makers in real organisational settings. This led Haka to conclude that:
"A comprehensive research program is necessary to determine how the product factor markets, the capital markets and legal/political/regulatory systems interact with firms' internal control systems... Most research to date has been piecemeal, looking at only parts of this challenging question. Related issues are how firm ownership structures interact with the markets and regulatory systems to affect investment decision-making and control." (p. 724)

However, our revisiting of the SIDM literature suggests that Haka may have missed some key contributions. This is a problem shared by Clancy and Collins (2014) who reviewed only a relatively small number of journals in accounting, finance and management from 2004 to 2013. Of the 110 articles they found on SIDM, only 10 were case study based (in contrast, 84 papers used analytical or archival methods). This led them to comment on the dearth of SIDM case study papers. However, as we will show, the SIDM literature has been informed by more case studies and organisation-based research than Haka or Clancy and Collins suggest. For example, Lumijärvi (1991) explored how subordinates influence SIDM, Nixon (1995) explored how external advisors were consulted in SIDM and Slagmulder (1997) examined issues of information asymmetry and strategic alignment.

The economic rationality underlying investment evaluation techniques has long been critiqued (e.g. Simon, 1976) and work based on other forms of rationality informed by socio-political (e.g. March, 1962; Pettigrew, 1973) and psychological behaviour (e.g. Kahneman and Tversky, 1979) has emerged. Indeed, important contributions have come from the management literature, largely emanating from Cyert and March's (1963) behavioural theory of the firm, such as the seminal study by Bower (1970) that examined SIDM from initiation to fruition. Hickson et al. (1986), Marsh et al. (1988) and Lumijärvi (1991) followed in this tradition. Sadly, this stream of work is relatively sparse. 
In the SIDM field, we have identified several important issues or themes such as ownership structures and external influences (Haka, 2007; Nixon, 1995; Harris et al., 2009), strategic alignment and information asymmetry (Slagmulder, 1997; Harris, 1999) and management structures and due diligence processes (Harris, 2007; Emmanuel et al., 2010). However, a key factor inhibiting cumulative knowledge-building and theorisation appears to be the absence of a consistent conceptual framework for carrying out and analysing field and case studies. The aim of this paper is to explore whether Stones' (2005) 'strong structuration theory' offers an appropriate theoretical framework to give us greater insight into these issues in future SIDM case studies. To do this we address the following research questions:

a. How have SIDM case studies been theorised before?

b. What are the key problems and issues in SIDM that need further research?

c. How/can SST be employed to analyse such problems?

d. What are the issues arising from using SST to theorise SIDM case studies?

Stones' (2005) 'strong structuration theory' (SST) - as it has come to be known - provides a helpful lens for SIDM research for several reasons. First, it has long been recognised that SIDM involves complex organisational processes that, as well as drawing on 'rational' calculative tools such as net present value analysis, are shaped by organisational rules, norms and politics (e.g. Bower, 1970; Pinches, 1997; Emmanuel et al., 2010). Hence, there are 'structures' at play in organisational SIDM, some of which are formal and, perhaps, imposed (such as legislative frameworks, markets, taxation regimes, and even analysis models) while others may be more tacit and self-determined (such as risk preferences and group decision-making norms). Further, while some actors with influence over SIDM are close to the decision making process - e.g. those who champion a strategic investment project and/or assemble, analyse and make the business case for it - others act more 'at a distance' - e.g. senior managers with ultimate powers of approval and authority to take decisions, strategic investment partners, or even suppliers and customers. Also, SST is a useful framework for analysing situated practices where structuration processes work to shape, embed and enable practices within an organisation, as is the case for SIDM.

The application of a SST theoretical lens highlights the importance of agents' knowledgeability of the contexts in which they and their organisations operate - a dimension previously neglected in most SIDM studies. Our aim is to enhance the comparability of future research outcomes and guide how SIDM cases are conducted, analysed and theorised. In order to illustrate its potential in this regard, we apply SST concepts to the reanalysis of four published SIDM case studies ${ }^{1}$. The purposes of this reanalysis are: to illustrate how SST could provide an appropriate lens for addressing the research questions posed by these SIDM studies; to demonstrate the potential of SST to offer additional insights to SIDM research; and to identify key methodological issues in using this approach to enhance our understanding of SIDM processes and practices.

The remainder of the paper is structured as follows. In section 2 we introduce the key concepts of SST and their application in accounting research generally, before proposing how SST concepts may be applied specifically to SIDM. We outline our method and approach to the selection and analysis of past SIDM studies in section 3 before presenting the results of our analysis in section 4 . In section 5 we reflect on the development of our SST-based analysis and suggest how SST might aid methodological development for future SIDM research. We then summarise our conclusions and contributions in section 6 .

\footnotetext{
${ }^{1}$ We use the term "case studies" to include all research that is organisationally situated and has regard to the decision-making context.
} 


\section{Strong structuration theory and management accounting research}

Structuration theory perspectives are not new to qualitative accounting studies, with a substantial body of research having already drawn on Giddens' structuration theory (see Englund and Gerdin, 2014 for a review). Giddens aimed to build a social theory of organisations that viewed interactions between individual 'agents' and group 'structures' as the essence of a social system that evolved as individuals adopted and developed a common set of rules and norms, mediated by their relative power positions (Giddens, 1979). Giddens set out three types of structure: signification (communication, which may be informed by organisational artefacts such as mission statements or strategic plans); domination (the exercise of power via interactions between individuals and their relative social positions); and legitimation (shared norms and associated sanctions, which may be reflected in organisational policies such as budget authorisations).

Giddens (1984) positions 'strategic conduct analysis' (agents' awareness of what they do and reflexivity about their practice) and 'institutional analysis' (repetitive reproduction of rules and resources) as elements of structuration theory that may be analysed separately as a form of methodological bracketing. Strategic conduct analysis is concerned with the hermeneutic ways in which human agents draw upon their understanding of the structures of signification, domination and legitimation. Giddens (1984, p. 373) argues that agents exercise power through the deployment of material (allocative) and human (authoritative) resources. Structuration theory (ST) views management accounting practices, including capital budgets, as structures of meaning that agents draw upon to guide their actions and embed power relationships (Roberts and Scapens, 1985; Macintosh and Scapens, 1991; Busco, 2009).

Examples of ST-based management accounting research include studies of: management by objectives (Alam et al., 2004; Dirsmith et al., 1997); costing systems (Hassan, 2010; Jack, 2005); enterprise resource planning systems (Hyvönen and Pellinen, 2006); budgets (Uddin and Tsamenyi, 2005); supply chains (Free, 2008); organisational change (Conrad, 2005; Joseph, 2006); and performance evaluation (Cowton and Dopson, 2002; Scapens, 2006). Whilst Giddens' ST has been applied to management accounting research and many elements of it have retained their importance, ST has also been subject to considerable criticism (Stones, 1991; Jones and Dugdale, 2001, Stones, 2005; Jack \& Kholeif, 2007; Coad and Herbert 2009). For example, Stones has issues with the methodological bracketing of institutional analysis within ST as it "retains no effective space for the structural-hermeneutic nexus of structuration theory" (Stones, 2005, p. 43). This acknowledges the fact that not everyone in an organisation will interpret situations or opportunities in the same way, though groups of people within organisations may share sense-making, especially when they have shared work experiences.

Another criticism of Giddens' ST is that it lacks a connection between the theory and empirics, so gives researchers little direct guidance on the conduct of empirical research (Jones and Dugdale, 2001 , p. 53). Stones $(2005$, p. 7) positions Giddens' ST as "trans-situational" relating to "ontology-ingeneral", concerned with concepts at the abstract level generalised to encompass all structures and agents across all contexts, but argues that Giddens misses the distinction between the philosophical and the substantive level. Stones argues that in order to understand a particular social phenomenon in a particular time and place, we should move to "ontology-in-situ" to develop bridging constructs between the philosophical and substantive levels of structuration (Stones, 2005, p. 8) and encourage empirical studies at the ontic level. The ontic is the "level at which the empirical can be sought" (Stones, 2005, p. 76). Giddens' approach, at the abstract level, is limited in substantive empirical research, and can be used only as a sensitising device or analytical tool (Jack \& Kholeif, 2007). Stones $(2005$, p. 77 ) also proposes a meso-level to bridge the abstract and ontic levels, which is 
where we position our contribution. We concur with Coad et al. (2015) that Stones (2005) offers a reinforced version of Giddens' theory to strengthen ST in order to make it empirically 'strong' by adding new dimensions.

The first of these new dimensions is that Stones suggests filling the institutional gap in Giddens' approach, to constitute a suitable theoretical framework for empirical research (Jack \& Kholeif, 2008). This occurs through a differentiation between the interpretive schemes, power and norms of agents-in-context and agents-in-focus. Agents-in-context represent the channels through which other agents understand structures, so are 'action-informing' (Stones, 2005, p. 91-92). Analysing the strategic context enables us to examine how agents-in-context shape decision makers' hermeneutic frames and their strategic conduct in SIDM.

The second contribution of Stones stems from adopting Cohen's (1989, p. 210) definition of "position-practices". Cohen (1989) posits position-practices to provide a link between Giddens' methodological bracketing of the institutional analysis of 'positions' and strategic conduct analysis of 'practices' (Stones, 2005, Jack \& Kholeif, 2007). Therefore 'position-practices' is seen as filling the "missing institutional link" in Giddens' work (Thrift, 1985, p. 618). The notion of position-practices provides an appropriate space to conceptualise the meso-level institutional link between structures and agency, as it acts as a bridge between the abstracted ontology-in-general and the substantive, empirically informed, 'ontic level' (Stones, 2005, p. 65).

Stones' SST is a holistic theory, which depicts structuration as a quadripartite intertwining of external structures, internal structures, active agency and outcomes. External structures are conditions of action that influence agents-in-focus, i.e. those closest to the action (Stones, 2005, pp. 93-94). Internal structures can be divided into (a) 'conjuncturally-specific' knowledge, which is "knowledge of interpretative schemes, power capacities and normative expectations and principles of the agents within context" (Stones, 2005, p. 91); and (b) 'general dispositions' that influence agents "naturally" and unconsciously (Stones, 2005, p. 88).

Some recent research in the management accounting literature draws on SST to explore the interactions between conjuncturally-specific knowledge and general-dispositions. For example, Jack \& Kholeif (2007) argue that these interactions raise conflicts about the organisational role of management accountants in ERP systems implementation, seeking to reproduce familiar structures based on their accountancy traditions. Likewise, Coad and Herbert (2009) found conflict between engineers and accountants in implementing a new management accounting system, where the engineers had previously maintained their own manual records and felt more empowered. This created a conflict between the engineers' general dispositions and the external structural context that required them to be receptive to changes in management accounting practices. Coad and Glyptis (2014, p. 158) illustrate the use of the SST concept of 'position-practices' in accounting and management control research, arguing that the concept:

“...more clearly sensitises accounting and control studies to how agents, situated in time-space contexts, draw upon their knowledge of situated practices, when engaged in the exercise of power, acts of communication and the imposition of sanctions".

In the SIDM field, there is evidence that managers use their intuition and tacit knowledge in forming their views about potentially complex projects and exercising their judgement using simplifying heuristics in personal and shared cognition (Harris et al., 2009). This aspect of SIDM research, which draws on psychology, can be accommodated in SST as part of the habitus of agents-in-focus. However, having used a psychological lens in her work, Harris $(2009 ; 2014)$ has focussed on agents' hermeneutic frames of meaning but neglected the 'independent causal influences' (external 
structures that "have the kind of causal influence on agents' lives that those agents do not have the physical capacity to control or resist"; Stones, 2005, p112.) present in the decision environment.

We see SST as offering a helpful lens for exploring managers' (agents-in-focus) interpretation and reaction to the external structures relevant to SIDM and their managerial judgment to improve our understanding of the SIDM process. In SIDM, external structures may include both the corporate strategies and control systems (inside the organisation) and the social, political and cultural dimensions of the macro decision environment (Hickson et al., 1986; Child and Lu, 1996; Elbanna and Child, 2007; and Carr et al., 2010). These important dimensions of the SIDM context may be incorporated in SST as "macro social and historical forces... [that]... contribute to the external conditions of action" (Greenhalgh and Stones, 2010, p. 1290).

Stones (2005, p. 122) emphasises the role of agents-in-context, which puts a useful spotlight on those who shape the decision-making environment, arguably neglected in the SIDM literature. SST explores the relational power of agents' 'position-practices' (Stones, 2005, p. 63), which provides clues as to how the phenomenon Giddens refers to as the dialectic of control may be interpreted. Whilst some SIDM research offers insights into the social process by which new projects are negotiated up through the management hierarchy (Mintzberg et al., 1976; Lumijärvi, 1991), it does not deal with the detail of conflict resolution in the SIDM process.

Most importantly for our analysis of SIDM case studies, the systematic attention to epistemology and methodology in SST enables us to explore the empirical detail of external structures as conditions of action, agents' context analysis, position-practices, internal structures, agents' knowledgeability and power in the 'structure-agent' relationship. SST also offers the 'meso-level of ontological abstraction' which helps us conceptualise SIDM across case studies, drawing out the common themes of SIDM practice from case comparison. The components of Stones' quadripartite framework enable us to empirically examine the complexity of relationships between agents and structures to enhance our understanding of SIDM. The SST conceptualisation of 'irresistible causal forces' (i.e. forces that agents can ignore only if they have the power and knowledge to 'do otherwise') helps us to differentiate between enabling and constraining effects of structures.

Following Stones' $(2005$, p.6) suggestion to combine SST with other approaches and Coad and Herbert's (2009) call to use SST flexibly, we identify the possibility of complementary theories or insights. We incorporate, for example, work using actor network theory (Miller and O'Leary, 2007; Huikku and Lukka, 2016) or personal construct theory (Harris, 1999, 2007) that may be used to illuminate aspects of agents' conduct analysis, general dispositions or habitus. In sum, we argue that SST offers a means by which we can better understand the socio-political context of SIDM without sacrificing the psychological constructs and notions of actor networks that have moved SIDM research forward in recent years.

\section{Methodology}

In applying SST to the reanalysis of published SIDM field studies, attention had to be given to two issues: how to select the studies for reanalysis; and how to apply elements of the quadripartite framework and the concepts of actor's knowledge, relations and dynamic processes to our reanalysis of each study.

\subsection{Selecting studies for reanalysis}

Our selection of published SIDM studies for reanalysis comprised several steps. First, we considered the range of publication outlets and dates to be searched. The sources drawn upon were accounting 
and management journals included in the ABI/INFORM (Complete) ProQuest database, since SIDM is a topic that spans the accounting and strategic management literatures. Our search period spanned January 1970 to January 2016. We chose 1970 as the start date because it was the year in which Joseph Bower's seminal book on SIDM case studies was published, marking the onset of the body of field research on this topic.

To identify publications on the topic of SIDM, we used the ProQuest database to identify peer reviewed publications within the specified date range that included any of the following terms within their abstracts: capital investment(s); capital budgeting; strategic investment(s). We also referred to previous literature reviews in this field - i.e. Emmanuel et al. (2010) and Clancy and Collins (2014) - to confirm that we had not missed any significant publications. We then reviewed the 108 publications identified via this search to ensure that their focus of enquiry was indeed SIDM, as defined in the introduction to this paper.

At this point, some publications were eliminated because they focused on short-term or financialtype investments rather than investments that reflected a long-term, strategic commitment by an organisation. We then further limited our database search to only those publications whose full-text included at least one of the following terms: case study/studies; field study/studies; fieldwork; interviews. We also checked that the remaining studies fell within our broad definition of 'case studies'. In applying this criterion, our main concern was to ensure that the study gave consideration to organisational context (i.e. organisational structures, processes, practices and actors). Hence, at this point we eliminated some studies that we found were based on: the mechanics (or frequency of use) of investment appraisal techniques; survey data, where the findings were not framed within any organisational context; experimental methods, where organisational context was absent or fictitious; and conceptual analysis that did not draw on empirical evidence.

The application of our selection criteria left us with a total of 18 publications (table 1 ) that reported field studies of SIDM in the period 1970-2016, 13 published in accounting journals and 5 in management journals. While we make no claim that this represents an exhaustive set of field studies on SIDM, this collection of papers captures the main body of this research. The studies vary greatly in terms of the trade-off between the magnitude and depth of data collected and therefore the style of analysis. They include four that claimed to use grounded theory, two using personal construct theory, two using actor network theory, one using practice theory and nine where there was no explicit statement about theory (deductive or inductive).

Table 1 here

Using Lukka and Vinnari's (2014) distinction between domain theory, which in our case would be a theory of SIDM, and method theory, which guides the collection and analysis of data, it could be argued that virtually none of these studies actually offer us a domain theory as such. Rather, they offer partial insights into the practice of SIDM viewed through a variety of theoretical lenses. We regard grounded theory as more of a method theory, since Strauss and Corbin (1990) provide a framework for coding qualitative data that is intended to produce local theory from the ground up. Whether this produces a domain theory or not is questionable. Personal construct theory is basically a theory of cognition, so comes from the domain of psychology and has associated methodologies for data collection and analysis (repertory grid technique and cognitive mapping), as employed by Harris $(1999,2007)$. Actor network theory (ANT) or the 'sociology of translation' (Callon, 1986) has its roots in sociology and was originally intended to examine the role of science and technology in society (Hassard, 2008) with a focus on the relationships between human and non-human 'actants'. This has some elements in common with SST, as noted by Greenhalgh and Stones (2010), though these are seldom acknowledged by other ANT adopters. Jörgensen and Messner (2010) was the only study explicitly using practice theory based on Schatzki (2002), which also has its roots in sociology, 
drawing on ideas from Giddens amongst others, and has been widely used in the strategic management domain.

Not everyone appreciates the distinction between domain and method theory made by Lukka and Vinnari (2014), where grounded theory is seen as a method theory designed for the coding and analysis of qualitative data, irrespective of the domain the researcher is working in. Indeed Lowe et al. (2016) argue that it is almost impossible to separate them in practice. We are similarly concerned that separating theories from other domains or disciplines from our own, such as strategy or psychology, could be counter-productive if it were to discourage the pragmatic blending of theories we advocate here to better explain SIDM practice. The studies we analyse all seek to explain SIDM practice in relation to people and process in an organisational context and we feel that SST can be adopted without discarding contributions from psychology or strategy.

We selected four of the eighteen papers for reanalysis to illustrate the application of SST. We selected these four papers in order to include examples of each of the four theory perspectives identified amongst the eighteen papers, i.e.: grounded theory, personal construct theory, practice theory and actor-network theory (see Table 1). In selecting a paper from each theory perspective, we chose single-organisation case studies since it seemed likely they would offer greater empirical richness in regard to context, processes and agency. However, in choosing between the four grounded theory papers, we selected Slagmulder (1997) because it draws on case studies across six different organisations in an attempt to develop a form of domain theory about SIDM practice. This provides an interesting contrast to the other three selected studies and allows us to reflect on how a SST lens could inform such an attempt at theory-building. Our reanalysis of the four papers is presented in section 4.

\subsection{Reanalysing the prior studies}

We chose not to use any text analysis software such as NVivo as we were not seeking to make a form-oriented content analysis (Vourvachis and Woodward, 2015), but a more nuanced analysis of the roles agents played and the ways in which structures were reproduced or changed. We immersed ourselves in both Stones' writings on SST and the papers being reanalysed, and relied on a discursive and reflexive approach amongst the research team members.

The following questions framed our reanalysis of each prior study:

1. What was the key research question addressed?

2. What theoretical lens was used?

3. What were the key findings/insights presented in the paper?

4. What do we see through the SST lens?

5. How could SST have helped to address the authors' original research question and to develop a domain theory of SIDM?

The approach we took to reanalysing the published papers on SIDM was as follows. Three of the coauthors on this paper looked at each of the papers that were reanalysed from the perspective of SST. First, two people looked at each paper separately and then met to discuss it. They presented their analysis to a third person who read the paper fresh and then cross-checked their own interpretation against those already presented. This third person also identified the most significant illustrations for SST analysis and compiled working notes. Where there were any disagreements as to appropriate interpretation, this was discussed across the co-author team. The findings from this reanalysis are presented in section 4 and insights from the process are discussed in section 5 . 


\section{Analysis}

The analysis of four papers presented here demonstrates how SST may offer insights when theorising from SIDM case studies. Of course, SST was not used as a theoretical lens in the original studies, so our task was to re-interpret the findings post hoc in order to assess whether SST offers a practicable and useful lens for analysing SIDM case studies.

\subsection{Harris (1999)}

Harris $(1999, \text { p. 347) })^{2}$ set out to address "one of the practical problems faced by managers when appraising strategic investment opportunities ... how to deal with the uncertainty of the outcomes".

This action research study was conducted in a European logistics company and became a longitudinal case study involving the participation of at least 100 managers over a period of seven years (Harris, 2009, p. xi). Harris studied the assessment of risk factors (mostly non-financial) in strategic project appraisal using personal construct theory (Kelly, 1955) to elicit managers' perceptions of the comparative riskiness of projects they had a shared experience of.

The depiction of SIDM (p. 352) shows a bottom-up process where project ideas were generated locally and business cases worked up and presented to the group board for approval. It shows feedback loops, highlighting the potential for information asymmetry and need for "executive knowledge adjustment". Harris (p. 366) concluded that further research was needed to explore team dynamics and political behaviour surrounding SIDM in group decision processes.

The research was undertaken during a period when technology was changing the modus operandi in the logistics sector, "characterized by large scale businesses applying high levels of technological expertise to the management of several steps in the value chain in order to provide specialized logistics services to clients" (p. 349). These general conditions formed part of the business environment that the top 100 managers attending the corporate conferences would have understood (agents' knowledgeability of their strategic context). However, their understanding of the behaviour of competitors they were bidding against when responding to invitations to tender (ITTs) in their local markets could be seen as divisional level conjuncturally-specific knowledge. There was evidence of information asymmetry amongst managers at different levels in the organisational hierarchy, such that the CFO was not always aware of possible projects being discussed at an early screening stage by divisional managers. Indeed the SIDM process model based on the case evidence (p. 352) showed that not all projects might complete the whole iterative process and all of its feedback (executive knowledge adjustment) loops.

The management teams formed clusters of agents-in-focus to produce a common set of risk attributes and weightings for the main types of strategic decisions they were familiar with, which they then applied each time another project of that type came up for consideration, "so developing and operationalizing their own metrics" (p. 354). In doing so, they shared their conjunturally-specific knowledge in discussing and agreeing the relevant project risk constructs and (re)ordered their priorities in agreeing the weightings of those attributes to be applied in their future SIDM. This illustrates an example of agents' conduct analysis. Clients were obviously powerful parties in relation to the agents-in-focus (position-practice relations; Stones, 2005, p. 94), as four of the key risk factors identified were customer related, i.e. 'cultural fit', 'quality of information' and 'demands of

\footnotetext{
${ }^{2}$ Some further details about the 1999 study were taken from a book published in 2009 that reported on a longitudinal study in the same organisation. Page references in this section all refer to the original paper unless stated otherwise.
} 
customer' and 'negotiating strength' (p. 370). These factors may be viewed as independent causal influences (Stones, 2005, p. 111) that could neither be ignored nor changed by the agents-in-focus.

The risk attributes labelled 'corporate factors' in the risk assessment grid; strategic fit; expertise; and image (or impact on company/brand reputation) may have been less clearly embedded in the hermeneutic frames of meaning of the managers at business unit or divisional level, though there appeared to be scope for agents-in-focus to manipulate the framing of their projects to claim a high level of strategic fit for projects they wanted to pursue. This is an example of how agents could use information asymmetry as an opportunity "to do otherwise" (Giddens, 1979, p. 56). The capital budgeting procedures "were set out in a paper which divisional finance directors had received from group head office" (p. 350) as part of the accepted rules or structure for SIDM, but this was supplemented by a user guide for the risk assessment technique (Harris, 2009, p. 98) developed through the action research. Capturing the risk perceptions for each project through a 'bottom-up' process became the agents' habituated practice, illustrating the dynamic nature of active agency.

Feedback from the participants in this action research (Harris, 2009, pp. 97-98) illustrates how the conjuncturally-specific knowledge aspect of internal structures evolved. Stones (2005, p. 25) observes that "the more adequate their knowledgeability of context, then the less likely they are to engage in actions that may lead to unintended consequences". The intention relates to that particular agent of course, which may differ in organisations where goal incongruence is observed. In this case, we can see agents-in-focus as being given freedom to express their views on the merits and riskiness of projects in their own way, enabling them to exercise managerial judgement. Agentsin-focus are also knowledgeable about how the agents-in-context on the group board encouraged change in SIDM practice by agreeing to participate in the research project in an attempt to reduce the hierarchical information asymmetry and improve management control.

From this case we can capture the following meso-level categories of actor's knowledgeability relevant to SIDM, which may be generalizable beyond this particular case:

1. Macro-level or global business environment

2. Country/local culture and micro-level business environment, market knowledge

3. Company strategy/structure, priorities of owners/corporate culture

4. Product/service delivery, local operations

5. Local demand, customers' needs

6. Project/investment opportunities

7. SID appraisal tools and techniques, capital budgeting procedures

8. Learning from past SIDM cases and outcomes of the SIDM process.

The group level managers could be seen as being more knowledgeable about 1, 3 and most likely 7 at their strategic level. The divisional level managers would be more knowledgeable about 2, 4 and 5 and the two manager levels may have different understandings of 6 and 8 from their perspectives, based on the fact that some possible projects never proceeded as far as the group board.

Using SST to analyse this case could have revealed more about the information asymmetry and the types of power asymmetries and forms of resistance at play in the position-practice relations. However, the use of PCT was effective in revealing agents' tacit knowledge, so we suggest it could be interesting for future studies to combine these two theories to use PCT as a basis for psychological analysis of agents' cognition within an SST framework. 


\subsection{Jörgensen and Messner (2010)}

Jörgensen and Messner's (2010) case study explored the relationship between accounting and strategy in complex new product development (NPD) projects. More specifically, the focus of the paper was to investigate how strategic objectives may be mobilised together with accounting information to make sense of particular design choices or action alternatives and to control the trajectory of the NPD process, and to what extent accounting information is implicated in strategising. The case organization was the research and development (R\&D) division in a manufacturing company selling analytical devices for quality control and processing of agricultural, food, pharmaceutical and chemical products. To respond to customer needs and decrease manufacturing costs, the organization made a strategic decision to adopt a modular product design approach. Using profitability calculations to evaluate such new modular products is problematic as modularity is characterised by a high degree of complexity and uncertainty which challenges the abstracted technical models. Applying a practice theory perspective (Schatzki, 2002), Jörgensen and Messner adopted an ethnographic approach and presented their case study data in the form of narrative, from which they theorised about the NPD decision-making process.

They observed divisional use of a stage-gate model in NPD processes, with a contribution ratio and a payback ratio calculated at each stage. They found that financial accountability was created through a set of rules by top management. However, between the stage-gates the general understanding, local knowledge and intuition of organisational actors (e.g. project managers) were more likely to be considered in making decisions. Based on this, Jörgensen and Messner suggested that there is a crucial role for bottom-up contributions to the strategising process, noting "local knowledge seems to play a stronger role for the crafting of practices in our case of NPD ... due to the high degree of uncertainty and complexity..." (p. 202). Since, in practice, it is not always possible to translate strategic considerations into accounting language, this study addressed a question about the extent to which organisational actors refer to them when evaluating alternative courses of action (p. 202).

The corporate growth strategy, and the pressure from headquarters to follow it, played a major role in the divisional management board's (e.g. CEO, R\&D director and production director) decision to approve the NPD project. Hence, using SST terminology, we begin by identifying the divisional management board as the agents-in-focus in this SIDM case who 'saw modularisation as an opportunity ... to contribute specifically to the growth strategy imposed on them from headquarters ...' (p. 193). We interpret this as part of the 'irresistible causal influences' defined by Stones (p. 111) as the divisional managers were not completely autonomous from the parent company, but felt they did not have the ability to resist and were pushed to accept the NPD project. In addition, other agents-in-context such as salespeople, engineers and project managers encouraged the management board to make such a decision.

The divisional management board created financial analyses at each stage of the decision process as a decision routine. However, the complexity and the uncertainty of the NPD project pushed these agents-in-focus to use their general understanding, local knowledge and experience to adapt the decision routine. Accordingly, the agents-in-focus engaged in active agency using their intuition and judgement. They "... believed in the idea [of modularisation] and the project [Alpha] was hereby authorised!" (p. 193). Also, Jörgensen and Messner noted that:

'The somewhat "intuitive" way in which the strategy of modularisation was decided upon ... reflected the company's practice of dealing with uncertainty in NPD projects more generally. The CEO and his management team knew that the spreadsheet model could not serve as an answer machine' (p. 193). 
Hence, the agents-in-focus used accounting numbers as an act of communication to legitimise the NPD project. They understood that the head office exercised its power by imposing financial accountability as formal rules. Accounting information could "enter the picture as a general understanding that guides actors' strategising efforts by reminding them of the ultimate importance of financial numbers' (p. 184). Thus, accounting numbers were still articulated to legitimise the process of making or justifying a strategic decision.

Although the agents-in-focus were knowledgeable and understood the misrepresentation of technical models they did not act otherwise; they still reproduced the technical structure (outcome). The agents-in-focus did not have adequate power to resist the production of technical structures (Stones, 2005, p. 115), but they did have sufficient power, based on their local knowledge, to exercise their own managerial judgement (active agency) and to ensure the accounting numbers they produced supported that decision.

SST could provide us useful alternative methods and vocabulary to illuminate how accounting is used in NPD decision-making. Addressing explicitly the meso-level of ontological scale could give us valuable insights into the 'dynamic processes' between accounting and strategy in developing new products, for example. It appears that through agents' contextual analysis divisional managers understand the importance of the growth strategy (an external structure) as a crucial corporate goal, and they 'actively' interact to comply with this 'situational' structure. In order to align with the growth strategy, agents-in-focus combine their two kinds of internal structures to re-order their priorities and enhance creativity and innovation through launching a modular product design approach. The outcome of this active agency is a shift towards the company approving more SIDs, illustrating how the structuration process between agents and structures occurs in a dynamic way.

Future studies could adopt a more ontic-level investigation to shed light on the relationship between accounting and strategy, and consequently focus on processes and practices at an individual level. This could enhance our understanding of how "in-situ" agents understand the contextual field in relation to their own values, duties and obligations and how they come to act in one way rather than another. Such ontic-level analysis using SST may contribute to a better meso-level understanding of SIDM by enabling cross-case comparison.

\subsection{Huikku and Lukka (2016)}

Huikku and Lukka (2016) investigated how the persuasiveness of self-assessment-based postcompletion auditing (PCA) reports of capital investment is constructed. Specifically, they explored how information in these reports rises to an acceptable quality level for them to agree to accept and use the reports for purposes such as enhancing organizational learning and discharging accountability. Self-assessment-based PCA is the most common way to conduct PCA, even though the extant literature suggests that self-auditing will entail obvious risks for the quality of the PCA reports in terms of data manipulation. The case organization was one of the major European forest companies where all the major capital investment projects are subjected to PCA. People with relevant knowledge about SIDM and PCA at different levels (mill, business area and group) were interviewed and 22 major SIDs reviewed in the company. Drawing on actor-network theory, the authors followed the complex process of constructing the persuasiveness of their PCA reports. Their findings suggest that three important elements likely function in the process of producing the PCA report. These are having an appropriate collective process of constructing the reports, the mobilisation of relatively objectified external and internal reference points for various pieces of information, and sufficient compliance with the guidance and reporting instructions in this process.

In this reanalysis we have identified the mill level management team (in the investing unit) as the agents-in-focus, i.e. the level in charge of conducting and compiling the report the PCA. In this 
context, the final PCA report can be considered the outcome of the structuration process. Even though the project manager in the mill compiled the report, its construction was a distributed activity. Many other people within the mill, such as controllers, sales directors and mill managers, were involved with the construction. They sought consensus about their shared truth by discussing and presenting several internal versions of the reports. They then needed to persuade the respective business area (BA) staff about the appropriateness of the draft reports. Often the reports were seriously challenged by BA staff and thereafter modified. Then, after receiving the green light from $B A$, the new versions of reports were delivered to the investment staff of the group (i.e. the function in charge of tasks such as developing and implementing the PCA system), who checked that all the materials had been enclosed before delivering the material to the members of the group level investment working group (IWG). IWG meetings (i.e. the group reviewing and approving the final PCA reports) were the forums where the mill manager and/or his/her staff members presented the report to be debated and challenged.

Hence, agents-in-context influencing the outcome are BA staff, investment staff of the group, and the group IWG. Additionally, all the major investment projects had steering groups closely following the cost budget, scheduling and technical specifications, to see that they were progressing to plan. Accordingly, the process of structuration was influenced by four distinct clusters of agents within the company (cf. Jack and Kholeif, 2008). Accounting artefacts, such as investment calculation principles and PCA guidelines, were provided by the group and strongly guided the production of PCA reports. These accounting artefacts can be seen to "represent position-practices that form part of an agent's external structures" (Coad et al., 2015, pp. 162-3). Theoretically, the outcome of PCA could also have changed these external structures.

PCA was conducted roughly one year after the investment project was commissioned by comparing ex ante and ex post profitability calculations (NPV, IRR and payback period). To facilitate comparisons between these calculations, PCA reports included both actual figures (past) and uncertain forecasted figures (future). Additionally, they included textual parts explaining actual and forecast performance. The persuasiveness of the actual figures could be considered high as they could be closely linked to the mill's accounting database (i.e. an external structure). The future estimates played a major role in the perceived success of the investment project. Generating figures for future periods is inherently demanding. Typically, the company derived these figures from the strategic plans of mills and BAs, and hence these figures were not merely calculated ad hoc for PCA purposes. In fact, experts beyond the company (agents-in-context), such as forecasting institutions and industrial consultants, had a key influence on determining core components in the company's plans and strategies. These included general economic outlooks, total demand forecasts for specific products and estimates for selling and raw material prices provided by these bodies.

Did the agents-in-focus have the ability to resist and regulate external influences and, hence, do otherwise? It appears not. Mill staff could not alone decide the final outcome of the report, as it was largely in the hands of others. The (draft) report was circulated within the organization and much discussion took place during the consensus-building process (habitus-related aspects). The authors synthesised the collective construction processes of PCA reports as follows: "Challenging discussions take place at all these levels and final reports are gradually produced" (p. 19). With regard to position-practice relations, BA and group levels were superior to mill staff and had the power to request modifications. The dominance of BA was constantly observed as one BA director explained (p. 18): "The first version that we received from the investing unit was immediately thrown back. They did it in a prettified manner and tried to find all positive arguments to make it look fine and beautiful." Additionally, external reference points (constraining external structures) greatly limited room for potential misrepresentations of information in the report. Namely, stories and figures have to be consistent with budgets and strategy, steering group and other discussions, historical 
performance, and mill reporting. The paper also shows communication aspects, with typical data manipulation methods (filtering and focusing; see also the above quote) appearing during the PCA processes.

As shown above, using SST could have directed the researchers to focus (even) more on the influence of external pressures in shaping the PCA report. Specifically, four distinct clusters of agents appear to play a major role in the structuration process. The use of a position-practice perspective illuminating social positions of different agents and their social interactions (Coad and Glyptis, 2014) could have given us invaluable insights to better understand and develop theory about the construction of the persuasiveness of PCA reports. This could have had the capacity to sensitise the investigation of the power-related aspects of the structuration process, for example. Explicit SSTguided attempts to identify agents-in-focus and agents-in-context and their power asymmetries may have been conducive to understanding and elaborating the genuine degree of independence of different parties, such as BA staff who at the end of the day seemed to have a strong say in the SIDM. Furthermore, more light could have been shed on the agents' conjuncturally-specific knowledge of structures within the position-practice relations by asking them how much they know about the processes, the history, the situation, and the context at hand.

\subsection{Slagmulder (1997)}

As noted in Section 3.1, Slagmulder (1997) took a rather different approach to the three cases reanalysed above. She adopted a grounded theory approach to investigate how and why management control systems (MCS) designed for SIDM are used to align SIDs with organizational strategies. However, rather than analysing a single case study, Slagmulder drew on case studies of ten manufacturing plant and equipment SIDs within six large, decentralised, public companies. We include this paper in our reanalysis because it represents an attempt to develop a domain "theory about MCS for SIDs and how they evolve to maintain strategic alignment" (p. 107) using evidence from multiple case studies. Hence, it offers a different perspective on how a SST lens could have informed such an effort.

Slagmulder identified the primary role of MCSs for SIDs as achieving alignment between the strategic investment and strategy. She noted that changes in key "environmental conditions" (organizational structure, competitive environment, or intended or emergent strategy) gave rise to misalignments between strategy and SIDs in the studied companies, thus creating a perceived need to adapt the MCS to restore strategic alignment.

Using SST vocabulary, conditions which exist independently of the agents-in-focus can in this study be seen as part of the external structures that shape the conditions for action. The companies' senior managers responded by adapting their MCS for SIDs (a key external structure from the perspective of the agents-in-focus) in various ways. These included: increasing project screening oversight; implementing more structured approval processes; involving senior managers early in the SIDM process; and introducing new, looser control mechanisms such as "approval in principle" (p. 131) or "rubber stamp[ing]" (p. 126) of projects. Hence, Slagmulder's findings emphasised the importance of considering how changes in some external structures can lead to problems of strategic misalignment that then trigger a need to reconsider how other external structures, such as MCS, can be altered to better direct SIDM. This restructuring can also be seen to modify agents-infocus' conjuncturally-specific knowledge, leading them to re-order their SIDM priorities. This is consistent with SST's recognition of how structuration processes entail the ongoing interplay between structure and agents via active agency and suggests that SST could provide a useful lens for extending Slagmulder's findings. 
In regard to the roles of agents, it is interesting to note that one of Slagmulder's criteria for selecting the studied investment projects was that "the principal individuals involved in the decision-making still have to be with the company" (p. 110). This suggests a concern to engage with the agents-infocus via her interviews with "operational managers who have been closely involved in particular investment projects and have thus interacted with the MCS for SIDs" (p. 107). However, Slagmulder focused on the active agency of top management in adapting the MCS around SIDM processes (and their stated reasons for these actions) and afforded rather less attention to the practices or perspectives of the agents-in-focus directly engaged in SIDM. Indeed, she notes (p. 104) that it was not her aim to examine "the roles that individuals play in the [decision-making] process". Hence, Slagmulder's analysis does not consider the relative power positions of individual agents engaged in SIDM processes within the case organisations. Understanding the influence of agency and positionpractices is further confounded by a lack of clarity as to whether the interviewed "financial and manufacturing executives from the top management team" (p. 107) were involved in the studied SIDs as agents-in-focus, or acted as agents-in-context via their role in designing the MCS that shaped SIDM practices. Slagmulder notes (pp. 117-118) that top management were able to adapt the MCS for SIDs by: introducing new control mechanisms; adjusting the tightness of controls such as investment hurdle rates; altering the level of formality required in SIDM by, for example, demanding more information; or changing the locus of SIDM.

The outcomes identified in Slagmulder's case studies comprise changes to aspects of the organisational MCS, as discussed above. These outcomes were achieved via the interactions between structures and agents. By paying more attention to the agents and their position-practice relations we might better understand the phenomenon of alignment between SID and strategy. For example, information asymmetry between horizontally and vertically located agents was suggested to be one of the major sources of strategic misalignment in Slagmulder's study. Applying an SST analytical lens could direct our attention to elaborating how information asymmetry is perceived in position-practice relations and how it influences the adaptation of control mechanisms. Additionally, it would be fruitful to shed light on the actors' knowledge of their situation; how do different agents perceive strategic misalignment per se and how do they interpret the actions of others to remedy the misalignments?

In sum, Slagmulder's aim of drawing on multiple case studies to develop a "theory about MCSs for SIDs and how they evolve to maintain strategic alignment" (p. 107; our underlining) seems impeded by a lack of consideration of agency and position-practices. This missing "how" element in her analysis would have been an integral component of an SST analysis and could have enriched Slagmulder's insights into the processes and interactions via which changes to MCS served to realign SIDM outcomes with organisational strategy. Hence, our consideration of Slagmulder's paper illustrates the potential contribution of SST concepts to developing domain theory about SIDM processes and practices.

\subsection{Analysis summary}

We appreciate that not every researcher wishes to investigate all aspects of the SIDM process in a holistic way, which is why we started each subsection above with a summary of the original research problem the authors set out to address. We also acknowledge that direct, cross-case comparison is infeasible when the focal research problems and theoretical perspectives of each study differ. Hence, we offer here a summary of what we have found from our reanalysis of these four studies, to establish what we could see through an SST lens that the original authors may not have realised using their original theoretical lens. We then discuss the relative utility of SST, as we see it, for theorising SIDM. 
In Harris (1999), we can see sufficient evidence about agents' knowledgeability to suggest a useful set of categories of SIDM knowledge to explore in future studies. It is unsurprising that we learn more about the conjuncturally-specific knowledge and habitus of agents-in-focus as the study was based on a theory of cognition and used a method of knowledge elicitation associated with personal construct theory. What we cannot learn enough about from this case, which an SST approach would have revealed, is the power dynamic between the agents at divisional and group levels in the organisation and how the independent causal influences impacted agency and hence the SIDM.

In Jörgensen and Messner (2010), we can see active agency as a dynamic process, where the agentsin-focus at company level realise the need to embrace the new group-wide growth strategy (a change in the external structures from time 1 to time 2 ) and re-order their priorities to ensure they can put forward more NPD proposals that can be justified both financially and strategically. They do this by creating a modular product that enables them to innovate more quickly (speeding up the NPDs' transit through the stage-gate process), more frequently and more cost effectively to meet the demands for growth. Whilst their use of practice theory enabled them to "illuminate these processes of strategising and the way they relate to accounting information ... the question arises to what extent organisational actors refer to either of them [strategy and accounting] when evaluating alternative courses of action" (p.203). We argue that, by using SST, they could have shed more light on this question, as the study could have explored more about the internal structures of conjuncturally-specific knowledge and practice-oriented habitus in producing practical action (active agency).

Huikku and Lukka (2016) focussed on post-decision controls and the accountability of agents for decisions taken in the SIDM process. We can see a potentially interesting pattern of position-practice relations emerging between the mill managers, the business area staff and the group level investment working group. However, this is only partially revealed through the ANT lens adopted. We argue that an SST approach would have revealed more about the types of power capacities and degrees and forms of resistance within these relations to contribute to our theorising of SIDM.

In Slagmulder (1997), we can see how top management used their power position to dominate by intervening to change management control systems in SIDM to address different types of perceived strategic misalignment. In SST terms, the hierarchical information asymmetry (both in terms of different levels of knowledge about the firm's strategy or about the project opportunities) appeared to give agents-in-focus the means by which to act otherwise and gain approval for projects that did not really fit the strategy as understood by top management. There was also evidence of horizontal asymmetry that was not fully explored in the original study. However, we argue that the grounded theory produced gave the actors insufficient voice to shed enough light on whose perceptions counted and whether agents at the business unit level took these changes fully on board or continued to act otherwise.

In sum, our reanalysis of each of these four papers has illustrated different aspects of how SST concepts can inform SIDM case research. Individually, these studies appear as four pieces of four different jigsaws about SIDM, each jigsaw building a different picture within a different frame. While our overlaying of these heterogeneous studies with a SST-informed lens cannot then render them directly comparable, we have begun to show how these disparate pieces could be seen as parts of a single SIDM jigsaw with a shared frame. We have also highlighted some 'missing pieces' where the SIDM picture could be fleshed out; these missing pieces became evident only when a consistent analytical framework was applied across this set of studies. Hence, our sense is that SST provides a useful and insightful lens for SIDM research. Its ability to generate insights within a consistent frame of analysis enhances the potential to build a domain theory of SIDM from future case studies across different times and spaces. 


\section{Reflections on adopting SST for SIDM case studies}

From our analysis, we have illustrated the potential for theorising SIDM studies through the lens of SST. However, our theorising has not been without issues. We reflect on some of these issues here in order to share the benefit of our travails with other researchers, so they may embark on fresh studies knowing some of the potential pitfalls we encountered.

Firstly, we were attempting reanalysis based on available evidence from past studies that took a different approach and employed non-SST theories. Therefore we were hindered both by the extent of evidence discernible from prior publications and by the fitness for purpose of that evidence to suit our SST lens. Neither of these issues need hinder future studies if SST is adopted soon enough in the research design to guide data collection as well as analysis. Despite these hindrances, we feel that a case can be made based on our reanalysis to encourage use of SST in future studies, in terms of the richer picture of SIDM practice it enables us to assemble.

Secondly, as a research team, we began our journey of developing this paper with varying degrees of understanding of the complexities of SST. This necessitated a considerable investment of our time (and the patience of the reviewers and editors) for us to begin to do justice to Stones and to the original authors whose work we were scrutinising. In recommending the use of SST in future SIDM studies therefore we wish to point out some of the SST concepts we tripped up on along the way.

The first of our initial stumbles was to roughly equate the people and process perspectives from earlier SIDM literature with agency and structure, without appreciating the ontological differences between these concepts. This was obviously a simplification too far, from which we have withdrawn. Whilst the people involved in SIDM may be seen as agents, they are certainly not a single homogeneous group. Rather, through the SST lens they form 'clusters' of agents who may or may not have a shared 'habitus', knowledge or understanding of their context. We learned that identifying the agents-in-focus and placing them within their network or field of position-practice relations (Stones, 2005, p. 94) is not as easy as it might first appear in SIDM studies. We also see that whilst processes may be part of structures and vice versa, they are by no means synonymous. Nor do they necessarily equate to the non-human actants in ANT, though accounting can play a part in both.

The second trap we fell in and out of on our SST journey (and comments made at conferences where we presented earlier versions of this paper suggest it may be a common misunderstanding) is the meaning of externality. For structuration theory generally and Stones specifically (2005, p. 84) external structures are "conditions of action, which have an existence that is autonomous from the agent-in-focus". However, in organisationally-based case studies of SIDM 'external' usually means something or someone outside the organisation. Again it is conceivable that a particular aspect of the wider context in which SIDM takes place, such as the proposed exit of Britain from the European Union (and the subsequent uncertainties for international trade, the mobility of the workforce etc.) could be perceived as both an external factor in organisational terms and part of the external structure in SST terms. However, as we have seen in our analysis, it is also possible for group level managers (internal to the organisation) to set conditions for action that impose external structures on those agents-in-focus making decisions at divisional level in the same organisation. We therefore raise this matter of the need for a more nuanced understanding of externality as a warning to others who may wish to adopt SST in their research journey to take care in identifying what is internal or external to an agent-in-focus. 
The third trap for us in interpreting Stones' $(2005$, p. 85 ) quadripartite nature of structuration was to see its elements as a sequential cycle that can easily be mapped against the lifecycle of a strategic decision in an organisation. Again, we now see a more nuanced form of active agency as a dynamic process that can change within time and space quite independently of the transit of a project through the SIDM process.

Reflecting on our analysis, we also identify several implications for methodological development in the SIDM field. The first of these issues concerns timing. Analysing SIDM studies using SST has pointed to the importance of tracing all the agents who influence these decisions, beginning with the agent-in-focus, the factors that shape the context for these decisions, and the structuration outcomes (changes to, or reinforcements of, external and internal structures) that result. However, the nature of SIDM, where the process of appraising and implementing an investment project can take months or years, means that relevant actors, structures and change processes can be discerned only over time. Stones $(2005, \mathrm{p} 126)$ also points to the need to involve "a number of different actors over a relatively extended period of time" to explain complex questions. Hence, SIDM research lends itself to longitudinal case studies. The challenge is that researchers may have access issues and/or may need to publish their research findings within shorter timescales.

It is conceivable that the researcher who relies on a single interview with each research participant is only able to capture a picture of SIDM at one point in time. However, in most interviews (whether the point is explicit or not) interviewees reflect on the past and comment on the changes that have taken place or the subsequent outcomes of that decision. Indeed, some researchers explicitly use stimulated recall (e.g. Harris, 1999) to ask interviewees to reflect on past events such as strategic investment projects or decisions that went badly or well. Others may design their research to engage with each participant across multiple periods, thus allowing interviewees to explain events or outcomes over time. Either can be legitimate means of conducting a longitudinal study and enabling a SST-informed analysis that appropriately captures the agents, structures and outcomes involved in SIDM.

It is pertinent here to say a little more about outcomes. Rather than focusing solely on the final investment decision 'outcome' (i.e. deciding whether or not to invest), the researcher viewing SIDM through an SST-informed lens is most interested in the whole complex process of interaction, negotiation, consensus and dissent that may produce both intended and unintended consequences. According to Huikku (2011), firms may change their SIDM instructions and procedures for example based on feedback obtained in post-completion auditing. By using a consistent theoretical lens - SST - to trace these structuration outcomes, theorisation can be better supported by a cumulative body of research that captures outcomes across differing SIDM times and spaces.

Another key methodological issue arising from our reanalysis pertains to the identity of agents and the implications for who researchers seek to interact with. The selection of informants should be focussed on the internal agents-in-focus, but would also benefit from explicit selection of informants who may be defined as agents-in-context, where possible. Interviews with head office personnel or one or two top managers in a divisionalised firm have proved insightful in some studies we reanalysed and would be crucial to observe the position-practices of agents more fully. There is also potential value in collecting evidence on the categories of conjuncturally-specific knowledge of agents in the practice of SIDM suggested in our analysis of the Harris (1999) case above.

A further important aspect of SIDM studies, to contribute to the management accounting literature, lies in capturing the use of accounting information in the SIDM process. Jörgensen and Messner (2010) found that in order to fit the firm's growth strategy agents-in-focus use accounting information to understand the strategic consideration of investment decisions. What is not clear is 
whether all agents-in-focus understand the meaning of the accounting information in the same way. Thus, SIDM lends itself to being investigated with what Stones $(2005, \mathrm{p} 126)$ describes as a 'composite research strategy' that shifts the spotlight from one agent-in-focus to another, who may be differently situated in relation to the structuration process.

In addition to that, external structures (i.e. conditions for action in SIDM) might be shaped or reproduced due to the power of internal structures (conjuncturally-specific knowledge and habitus). Not all of the original studies in our reanalysis sought to expose the power of internal structures in exercising agency. Hence, using SST would help to achieve this either by bringing all dimensions of agency and structure into focus or by designing a study to focus on a particular aspect in more detail.

We suggest that in adopting SST for SIDM studies, researchers should identify where various agents fit into the organisational hierarchy, but to look beyond this for examples of how power is exercised in the deployment of resources. An important stage in the SIDM process involves post-completion audit to close the feedback loops and facilitate learning, which also fits the SST notion of active agency. We therefore urge researchers to make the elements of agency more explicit by revealing the learning and feedback loops in the SIDM process and noting changes in practice.

We acknowledge that the researchers whose work we have reanalysed in this paper did not necessarily set out with such a plan in mind. However, their studies have revealed sufficient evidence of these matters for us to conclude that it would not require too big a shift in research design for future studies to accommodate the use of SST, but it may require a bigger shift in the researcher's ontological position. By employing SST as a consistent and comprehensive theoretical framework, we suggest future cases studies may be both more informative and more comparable.

\section{Conclusions}

Our paper responds to the call for researchers to draw on Stones' (2005) strong structuration theory to inform studies of management and accounting (Coad and Herbert, 2009; Jack and Kholeif, 2007, 2008; Coad et al., 2015). Our key contribution is to propose a new way of theorising SIDM research based on applying concepts from strong structuration theory to the SIDM process. We argue that by applying Stones' concepts of the knowledgeability of agents and the power asymmetries and forms of resistance in position-practice relations to future case studies we can enrich our understanding of SIDM. And, given the turbulent and dynamic nature of the contemporary global business environment, these dynamic processes are likely to become increasingly important in understanding and theorising SIDM by incorporating more of a sense of the web of position-practice relations (Stones, 2005, p. 128). The use of SST also highlights the need to reflect on the interactions between the elements of agency and structure within SIDM, rather than seeing them as separable categories.

We applied SST concepts to past research by reanalysing a set of published SIDM case studies. This reanalysis demonstrated that SST can usefully be applied to SIDM studies. It also revealed that some prior SIDM studies give agents insufficient voice in the sense that SST requires for us to see how structuration shapes SIDM. We note the Jörgensen and Messner case as an exception in that they used significant amounts of narrative in their paper. However, their lack of interest in structuration meant that not all of the narrative was necessarily useful in our SST-based analysis. We also noted some challenges in using SST for the reanalysis of prior SIDM field studies. In particular, it was difficult to ensure the consistent interpretation of prior findings, particularly when it came to making judgements about the position-practice relations of agents in SIDM. However, we found that a team approach to discussing these challenges served to strengthen the application, so we recommend this approach to other researchers. 
To build a strong domain theory around SIDM we suggest that SST holds greater promise than either grounded theory or practice theory as it guides the researcher towards unpicking the complex social processes of human interaction. This is also arguably the case with ANT, which is possibly why we found the Huikku and Lukka (2016) case easier to reanalyse using SST than the other studies. However, ANT does not necessarily shed sufficient light on the agents' knowledgeability, nor on the dynamics of action the network of actors employs. We see SST as better suited than the alternatives to the study of SIDM in a holistic sense.

There is one point upon which we might disagree with Stones. This point is his assertion (Stones, 2005 , pp. 58 \& 113) that Giddens "over-emphasises" or "gives too much weight to" agents' ability to do otherwise. We feel that in the context of SIDM we have revealed this potential resistance, especially where information asymmetry allows, and that we have only scratched the surface of this problem in the domain of management accounting. We therefore suggest that researchers using SST might also find small areas where Giddens speaks to us more clearly than Stones. However, overall we find Stones' SST, especially in terms of the ontological levels he proposes, a suitable way of theorising SIDM. We also conclude, referring back to the current debate about method versus domain theory, that SST is not so much a method theory like grounded theory, but a theory from the domain of sociology that can help us in our quest to build theory in our domain of management accounting by viewing SIDM as a dynamic social process.

We envisage SST having utility in addressing a range of research problems such as: how SIDM is impacted by changing external factors and how this change occurs (i.e. the impact of agents-incontext as well as the active agency of agents-in-focus); how organisational learning is facilitated by feedback aspects of SIDM (since the outcomes of active agency, in terms of new or adapted structures and practices, are highlighted); isomorphism and/or differentiation effects in global SIDM practice (facilitated by the comparison of studies across different times and spaces); and the closer examination of not just what accounting information is used in SIDM, but also how it is used and how its use is shaped by agents. Hence, we suggest SST has the potential for broad applicability if viewed as a dynamic and flexible theory that may evolve through wider use as researchers resolve further issues in its application to SIDM.

This paper responds to calls to enhance the potential to theorise from case studies (Berry and Otley, 2004; Eisenhardt and Graebner, 2007) by proposing SST to facilitate theorising at the meso-level from case studies that provide rich and detailed research evidence at the ontic level. We invite management accounting researchers to adopt SST in their future SIDM research, both in guiding the design of their studies and developing new research questions, and in building on the work of others (Berry and Otley, 2004, p. 244) to enhance the theory and practice of SIDM. 


\section{$\underline{\text { References }}$}

Alam, A., Lawrence S. and Nandan, R. (2004), "Accounting for economic development in the context of post-colonialism: the Fijian experience", Critical Perspectives on Accounting, Vol. 15 No. 1, 13557.

Alkaraan, F. and Northcott, D. (2006), "Capital investment decision-making: a role for strategic management accounting?" British Accounting Review, Vol. 38 No. 2, pp. 149-173.

Berry, A. J. and Otley, D. T. (2004), "Case-Based Research in Accounting" in C. Humphrey and B. Lee (eds) The Real Life Guide to Accounting Research, Oxford: Elsevier, 231-255.

Bower, J. L. (1970), Managing the Resource Allocation Process: A Study of Corporate Planning and Investment, Boston, MA: Harvard Business School.

Busco, C. (2009), "Giddens' structuration theory and its implications for management accounting research", Journal of Management \& Governance, Vol. 13 No. 3, pp. 249-260.

Callon, M. (1986), "Some elements of a sociology of translation: domestication of the scallops and the fishermen of St. Brieuc Bay" in Law, J. (ed.) Power, Action, and Belief: A New Sociology of Knowledge. London: Routledge, pp. 196-233.

Carr, C. and Harris, S. (2004), "The impact of diverse national values on strategic investment decisions in the context of globalization", International Journal of Cross Cultural Management, Vol. 4, pp. 77-99.

Carr, C., Kolehmainen, K. and Mitchell, F. (2010), "Strategic investment decision-making practices: a contextual approach", Management Accounting Research, Vol. 21 No. 3, pp. 167-184.

Carr, C. and Tomkins, C. (1996), "Strategic investment decisions: The importance of SCM. A comparative analysis of 51 case studies in UK, US and German companies", Management Accounting Research, Vol. 7 No. 2, pp. 199-217.

Carr, C. and Tomkins, C. (1998), "Context, culture and the role of the finance function in strategic decisions: A comparative analysis of Britain, Germany, the USA and Japan", Management Accounting Research, Vol. 9 Issue 2, pp. 213-239.

Child, J. and Lu, Y. (1996), "Institutional constraints on economic reform: the case of investment decisions in China", Organization Science, Vol. 7 No. 1, pp. 60-77.

Clancy, D. K. and Collins, D. (2014), "Capital Budgeting Research and Practice: The State of the Art", in M. J. Epstein and J. Y. Lee (eds.) Advances in Management Accounting (Volume 24) Emerald: Bradford, pp. 117-161.

Coad, A. and Herbert, P. (2009), "Back to the future: new potential for structuration theory in management accounting research?" Management Accounting Research, Vol. 20 No. 3, pp. 177-192.

Coad, A., Jack, L. and Kholeif, A. (2015), "Structuration theory: reflections on its further potential for management accounting research", Qualitative Research in Accounting \& Management, Vol. 12 No. 2, pp.153-171. 
Coad, A. and Glyptis, L. (2014), "Structuration: a position-practice perspective and an illustrative study, Critical Perspectives on Accounting, Vol. 25 No. 2, pp. 142-161.

Cohen, J. (1989), Structuration theory: Anthony Giddens and the structuration of social life, MacMillan: London.

Collier, P. and Gregory, A. (1995), "Investment appraisal in service industries: A field study analysis of the UK hotels sector", Management Accounting Research, Vol. 6 No. 1, pp. 33-57.

Conrad, L. (2005), "A structuration analysis of accounting systems and systems of accountability in the privatised gas industry", Critical Perspectives on Accounting, Vol. 16 No. 1, pp. 1-26.

Cowton, J. and Dopson, S. (2002), "Foucault's prison? Management control in an automotive distributor", Management Accounting Research, Vol. 13 No. 2, pp. 191-213.

Cyert, R. and March, J. E. (1963), A Behavioral Theory of the Firm, Englewood Cliffs, NJ: Prentice Hall.

Dirsmith, W., Heian B. and Covaleski, A. (1997), "Structure and agency in an institutionalized setting: the application and social transformation of controls in the big six", Accounting Organizations and Society, Vol. 22 No. 1, pp. 1-27.

Eisenhardt, K. M. (1989), "Making fast strategic decisions in high-velocity environments", Academy of Management Journal, Vol. 32 No. 3, pp. 543-576.

Eisenhardt, K. M. \& Graebner, M. E. (2007), "Theory Building from Cases: Opportunities and Challenges." Academy of Management Journal, Vol. 50 No. 1, pp. 25-32.

Elbanna, S. and Child, J. (2007), "The influence of decision, environmental and firm characteristics on the rationality of strategic decision-making", Journal of Management Studies, Vol. 44 No. 4, pp. 56191.

Emmanuel, C., Harris, E. and Komakech, S. (2010), "Towards a Better Understanding of Capital Investment Decisions," Journal of Accounting and Organizational Change, Vol. 6 No. 4, pp. 477-504.

Englund, H. and Gerdin, J. (2014), "Structuration Theory in Accounting Research: Applications and accountability", Critical Perspectives on Accounting, Vol. 25 No. 2, pp. 162-180.

Free, C. (2008), "Walking the talk? Supply chain accounting and trust among UK supermarkets and suppliers", Accounting Organizations and Society, Vol. 33 No. 6, pp. 629-62.

Giddens. A. (1979), Central Problems in Social Theory, Macmillan, London

Giddens, A. (1984), The Constitution of Society, Polity Press, Cambridge.

Greenhalgh, T. and Stones, R. (2010), "Theorising big IT programmes in healthcare: strong structuration theory meets actor-network theory", Social Science \& Medicine, Vol. 70 No. 9, pp. 1285-1294.

Haka, S. F. (2007), "A review of the literature on capital budgeting and investment appraisal: Past present and future musings". In Handbook of Management Accounting Research (Vol. 2) (Eds, C. Chapman, A. Hopwood, and M. Shields), North Holland: Elsevier, pp. 697-728. 
Harris, E. (1999), "Project risk assessment: A European field study", British Accounting Review, Vol. 31 No. 3, pp. 347-371.

Harris, E. (2007), "How managers construe risk in business acquisitions", International Journal of Risk Assessment and Management, Vol. 7 No. 8, pp. 1057-1073.

Harris, E. (2009), Strategic Project Risk Appraisal and Management, Farnham: Gower. 377pp.

Harris, E. (2014), "Feel the risk: Strategic investment decisions in an uncertain world". In Management Control and Uncertainty (Eds, D. Otley and K. Soin), Palgrave McMillan, pp. 343-377.

Harris, E., Emmanuel, C. and Komakech, S. (2009), Managerial Judgement and Strategic Investment Decisions, Oxford: Elsevier.

Hassan, M. (2010), "Understanding the behavioural aspects of costing systems in public health organisations", International Journal of Behavioural Accounting and Finance, Vol. 1 No. 3, pp. 207223.

Hassard, J. (2008), "Actor Network Theory" in Thorpe, R. and Holt, R. (eds) The Sage Dictionary of Qualitative Management Research, London: Sage, pp.22-24.

Hickson, J., Butler, J., Cray, D., Mallory, R. and Wilson, C. (1986), Top Decisions: Strategic DecisionMaking in Organizations, Blackwell, Oxford.

Hopwood, A. (2009), "Reflections and projections - and many, many thanks", Accounting, Organizations and Society, Vol. 34 No. 8, pp. 887-894.

Huikku, J. (2011), Design of a post-completion auditing system for organizational learning, The Finnish Journal of Business Economics, Vol. 60 No. 2, pp. 173-212.

Huikku, J. and Lukka, K. (2016), "The construction of persuasiveness of self-assessment-based postcompletion auditing reports", Accounting and Business Research, Vol. 43 No. 3, pp. 243-277.

Hyvönen, T. and Pellinen, J. (2006), "The role of standard software packages in mediating management accounting knowledge", Qualitative Research in Accounting \& Management, Vol. 3 No. 2, pp. 145-160.

Jack, L. (2005), "Stocks of knowledge, simplification and unintended consequences: the persistence of post-war accounting practices in UK agriculture", Management Accounting Research, Vol. 16 No. 1, pp. 59-79.

Jack, L. and Kholeif, A. (2007), "Introducing strong structuration theory for informing qualitative case studies in organization, management and accounting research", Qualitative Research in Organizations and Management, Vol.2 No.3, pp. 208-225.

Jack, L. and Kholeif, A. (2008), "Enterprise resource planning and a contest to limit the role of management accountants: a strong structuration perspective", Accounting Forum, Vol. 32 No. 1, pp. $30-45$.

Jones, T. and Dugdale, D. (2001), "The concept of an accounting regime", Critical Perspectives on Accounting, Vol. 12 No. 1, pp. 35-63. 
Jörgensen, B. \& Messner, M. (2010), "Accounting and strategizing: A case study from new product development", Accounting, Organizations and Society, Vol. 35 No. 2, pp. 184-204.

Joseph, G. (2006), "Understanding developments in the management information value chain from a structuration theory framework", International Journal of Accounting Information Systems, Vol. 7 No. 4, pp. 319-41.

Kahneman, D. and Tversky, A. (1979), "Prospect theory: An analysis of decision under risk", Econometrica, Vol. 47 No. 2, pp. 263-291.

Kelly, G. A. (1955), The Psychology of Personal Constructs. London: Norton.

King, P. (1975), "Is the emphasis of capital budgeting theory misplaced?" Journal of Business Finance and Accounting, Vol. 2 No. 1, pp. 69-82.

Lowe, A., De Loo, I. and Nama, Y. (2016), "cutting the Gordian knot?: a response to Lukka and Vinnari (2014)" Accounting, Auditing \& Accountability Journal, Vol. 29 No. 2, pp.305-316

Lukka, K. and Vinnari, E. (2014), "Domain theory and method theory in management accounting research", Accounting, Auditing \& Accountability Journal, Vol. 27 No. 8, pp.1308-1338.

Lumijärvi, O.P. (1991), "Selling of capital investments to top management", Management Accounting Research, Vol. 2 No. 3, pp. 171-188.

Macintosh, N. and Scapens, R. (1991), "Management accounting and control systems: a structuration theory analysis", Journal of Management Accounting Research, Vol. 3 No. 3, pp. 131158.

March, J. G. (1962), "The Business Firm as a Political Coalition", Journal of Politics, Vol. 24, pp662678.

Maritan, C. A. (2001), "Capital Investment as Investing in Organizational Capabilities: An empirically grounded process model", Academy of Management Journal, Vol. 44 No. 3, pp. 513-531.

Marsh, R., Barwise, P., Thomas, K. and Wensley, C. (1988), Managing Strategic Investment Decisions, In Competitiveness and the Management Process, (ed., A. Pettigrew), Oxford: Blackwell, 86-136.

Miller, P. and O'Leary, T. (1997), “Capital budgeting practices and complementarity relations in the transition to modern manufacture: A field-based analysis", Journal of Accounting Research, Vol. 35 No. 2, pp. 257-271.

Miller, P. and O'Leary, T. (2007), "Mediating instruments and making markets: Capital budgeting, science and the economy", Accounting, Organizations and Society, Vol. 32 No. 7-8, pp. 701-734.

Mintzberg, H., Raisinghani, D. and Théorêt, A. (1976), "The structure of 'unstructured' decision processes", Administrative Science Quarterly, Vol. 21 No. 2, pp. 246-275.

Nixon, B. (1995), "Technology investment and management accounting practice", British Journal of Management, Vol. 6 No. 4, pp. 271-288. 
Otley, D. (2016), "The contingency theory of management accounting and control: 1980-2014", Management Accounting Research, http://dx.doi.org/10.1016/j.mar.2016.02.001

Pettigrew, A. (1973), The Politics of Organisational Decision-making, London: Tavistock.

Pinches, G. E. (1997), "The Use of NPV in Newly Industrialised and Developing Countries: aka 'What have we ignored?", Managerial Finance, Vol. 23 No. 9, pp. 24-45.

Roberts, J. and Scapens, R. (1985), "Accounting systems and systems of accountability understanding accounting practices in their organizational contexts", Accounting Organizations and Society, Vol. 10 No. 4, pp. 443-456.

Scapens, R. (2006), "Understanding management accounting practices: a personal journey", The British Accounting Review, Vol. 38 No. 1, pp. 1-30.

Schatzki, T. R. (2002), The Site of the Social: A philosophical account of the constitution of social life and change, University Park, PA: Pennsylvania State University Press.

Simon, H. A. (1976), Administrative Behavior: A Study of Decision-Making Processes in Administrative Organization ( $3^{\text {rd }}$ Ed.), New York, NY: The Free Press.

Slagmulder, R. (1997), "Using management control systems to achieve alignment between strategic investment decisions and strategy", Management Accounting Research, Vol. 8 No. 1, pp. 103-139.

Stones, R. (1991), "Strategic context analysis: a new research strategy for structuration theory, Sociology, Vol. 25 No. 4, pp. 673-695.

Stones, R. (2005), Structuration Theory, Basingstoke: Palgrave.

Strauss, A. and Corbin, J. (1990), Basics of Qualitative Research: Grounded Theory Procedures and Techniques. Newbury Park, CA: Sage.

Sykianakis, N. \& Bellas, A. (2005), "The foreign direct investment decision-making process: Strategy, politics and uses of management accounting information", Managerial Auditing Journal, Vol. 20 No 9, pp. 954-969.

Thrift, N. (1985), "Bear and mouse or bear and tree? Anthony Giddens' reconstitution of social theory", Sociology, Vol. 19 No. 4, pp. 609-23.

Uddin, S. and Tsamenyi, M. (2005), "Public sector reforms and the public interest: a case study of accounting control changes and performance monitoring in a Ghanaian state-owned enterprise", Accounting, Auditing and Accountability Journal, Vol. 18 No. 5, pp. 648-674.

Vourvachis, P. and Woodward, T. (2015), "Content analysis in social and environmental reporting research: trends and challenges", Journal of Applied Accounting Research, Vol. 16 No. 2, pp. 166-195. 
Table 1 SIDM case studies in the prior literature

\begin{tabular}{|c|c|c|}
\hline \multirow[t]{2}{*}{ Paper } & \multicolumn{2}{|l|}{ Case study details } \\
\hline & Focus of enquiry \& Setting & Theory \\
\hline $\begin{array}{l}\text { Carr \& Tomkins (1996) } \\
\text { MAR }\end{array}$ & $\begin{array}{l}\text { Use of strategic cost management tools in SIDM in } 44 \text { motor vehicle } \\
\text { component companies in UK \& Germany. }\end{array}$ & Grounded theory \\
\hline $\begin{array}{l}\text { Carr \& Tomkins (1998) } \\
\text { MAR }\end{array}$ & $\begin{array}{l}\text { Strategic styles (context and culture) in SIDM in } 71 \text { motor vehicle } \\
\text { component companies in UK, US, Japan \& Germany }\end{array}$ & - \\
\hline $\begin{array}{l}\text { Carr \& Harris (2004) } \\
\text { CCM }\end{array}$ & $\begin{array}{l}\text { Effect of national values on SIDM. Cross-case comparison in } 4 \text { motor } \\
\text { vehicle component firms in UK, US, Japan \& Germany }\end{array}$ & - \\
\hline $\begin{array}{l}\text { Carr et al. (2010) } \\
\text { MAR }\end{array}$ & $\begin{array}{l}\text { Contextual categories (market creators, value creators, refocusers \& } \\
\text { restructurers) in } 14 \text { SIDs in motor component \& telecoms firms }\end{array}$ & - \\
\hline $\begin{array}{l}\text { Collier \& Gregory (1995) } \\
\text { MAR }\end{array}$ & SIDM processes in 6 hotel companies. & - \\
\hline $\begin{array}{l}\text { Eisenhardt (1989) } \\
\text { AMJ }\end{array}$ & $\begin{array}{l}\text { Speed of SIDM (mostly NPD decisions) in } 8 \text { US microcomputer } \\
\text { firms. }\end{array}$ & Grounded theory \\
\hline $\begin{array}{l}\text { Harris (1999) } \\
\text { BAR }\end{array}$ & Risk constructs in 12 SIDs in a European logistics company. & $\begin{array}{l}\text { Personal construct } \\
\text { theory }\end{array}$ \\
\hline $\begin{array}{l}\text { Harris (2007) } \\
\text { IJRAM }\end{array}$ & $\begin{array}{l}\text { Risk constructs in } 4 \text { business acquisition decisions in a European } \\
\text { logistics company. }\end{array}$ & $\begin{array}{c}\text { Personal construct } \\
\text { theory }\end{array}$ \\
\hline $\begin{array}{l}\text { Huikku \& Lukka (2016) } \\
\text { ABR }\end{array}$ & $\begin{array}{l}\text { Post-completion auditing of } 22 \text { SIDs in a European forest } \\
\text { company. }\end{array}$ & $\begin{array}{c}\text { Actor-network } \\
\text { theory }\end{array}$ \\
\hline $\begin{array}{l}\text { Jörgensen \& Messner (2010) } \\
\text { AOS }\end{array}$ & $\begin{array}{l}\text { Relationship between accounting and strategy in a complex NPD } \\
\text { project in a Danish manufacturing company. }\end{array}$ & Practice theory \\
\hline $\begin{array}{l}\text { King (1975) } \\
\text { JBFA }\end{array}$ & Process of SIDM based on 2 SIDs in a large UK firm. & - \\
\hline $\begin{array}{l}\text { Lumijärvi (1991) } \\
\text { MAR }\end{array}$ & $\begin{array}{l}\text { Subordinates' influence on multiple SIDs in large manufacturing firm } \\
\text { in Finland. }\end{array}$ & - \\
\hline $\begin{array}{l}\text { Miller \& O’Leary (1997) } \\
\text { JAR }\end{array}$ & $\begin{array}{l}\text { One major SID program investing in modern manufacturing } \\
\text { technology in Caterpillar (a US firm). }\end{array}$ & - \\
\hline $\begin{array}{l}\text { Miller \& O’Leary (2007) } \\
\text { AOS }\end{array}$ & $\begin{array}{l}\text { Role of roadmaps in inter/intra-firm SIDs. One mega high tech NPD } \\
\text { Project in Intel Corporation. }\end{array}$ & Actor-network theory \\
\hline $\begin{array}{l}\text { Mintzberg et al. (1976) } \\
\text { ASQ }\end{array}$ & SIDM processes in 25 organizations in Canada. & - \\
\hline $\begin{array}{l}\text { Nixon (1995) } \\
\text { BJM }\end{array}$ & $\begin{array}{l}\text { Non-financial aspects in SIDM: NPD projects in } 3 \text { US and } 3 \text { UK } \\
\text { manufacturing companies. }\end{array}$ & Grounded theory \\
\hline $\begin{array}{l}\text { Slagmulder (1997) } \\
\text { MAR }\end{array}$ & $\begin{array}{l}\text { Alignment between SIDs and strategy. } 10 \text { SIDs in } 6 \text { European } \\
\text { manufacturing firms. }\end{array}$ & Grounded theory \\
\hline $\begin{array}{l}\text { Sykianakis \& Bellas (2005) } \\
\text { MAJ }\end{array}$ & $\begin{array}{l}\text { SIDM process in FDI decision-making in a Greek ice cream } \\
\text { manufacturer. }\end{array}$ & - \\
\hline
\end{tabular}

Note: the studies selected for reanalysis are highlighted. 